University of Nebraska - Lincoln

DigitalCommons@University of Nebraska - Lincoln

1990

\title{
Comparative Attraction of Four Different Fiberglass Traps to Various Age and Sex Classes of Stable Fly (Diptera: Muscidae) Adults
}

Jerome Hogsette

USDA

Joseph Ruff

John A. Mulrennan, Sr. Research Laboratory

Follow this and additional works at: https://digitalcommons.unl.edu/usdaarsfacpub

Part of the Agricultural Science Commons

Hogsette, Jerome and Ruff, Joseph, "Comparative Attraction of Four Different Fiberglass Traps to Various Age and Sex Classes of Stable Fly (Diptera: Muscidae) Adults" (1990). Publications from USDA-ARS / UNL Faculty. 1001.

https://digitalcommons.unl.edu/usdaarsfacpub/1001

This Article is brought to you for free and open access by the U.S. Department of Agriculture: Agricultural Research Service, Lincoln, Nebraska at DigitalCommons@University of Nebraska - Lincoln. It has been accepted for inclusion in Publications from USDA-ARS / UNL Faculty by an authorized administrator of DigitalCommons@University of Nebraska - Lincoln. 


\title{
Comparative Attraction of Four Different Fiberglass Traps to Various Age and Sex Classes of Stable Fly (Diptera: Muscidae) Adults ${ }^{1}$
}

\author{
JEROME A. HOGSETTE ${ }^{2}$ AND JOSEPH P. RUFF ${ }^{3}$
}

\begin{abstract}
J. Econ. Entomol. 83(3): 883-886 (1990)
ABSTRACT An Alsynite cylinder trap and three different Williams cross-configuration traps with three adhesives were compared to determine their relative attraction to stable fly, Stomoxys calcitrans (L.), adults. Williams traps coated with Olson Sticky Stuff performed as well as Williams traps coated with Tack Trap, thus allowing fly samples collected with either adhesive to be compared. The cylinder trap captured fewer total flies, but more flies per $\mathrm{cm}^{2}$ than any of the Williams traps. Sex ratio of flies captured on the cylinder trap was 50:50, while the three Williams traps captured predominantly males. The cylinder trap captured a larger percentage of nulliparous, unmated females than did the other traps tested.
\end{abstract}

KEY WORDS Insecta, Stomoxys calcitrans (L.), traps, adhesives

MANY TYPES OF TRAPS such as those that use light (Morgan et al. 1970, Pickens et al. 1972, Schreck et al. 1975), dead flies (Williams et al. 1977), animals (Roberts 1972, Williams et al. 1977), and $\mathrm{CO}_{2}$ (Roberts 1972) have been devised to sample adult populations of the stable fly, Stomoxys calcitrans (L.). Bailey et al. (1973) may have been the first to try adhesive-coated surfaces, but the experiments with Alsynite fiberglass by Williams (1973) resulted in the design of the highly efficient, relatively inexpensive, portable, adhesive-coated traps which are now ubiquitous in stable tly research. The basic trap, known as the Williams trap, has been modified for use as a marking device (Hogsette 1983) and a toxicant device (Meifert et al. 1978, Koehler \& Patterson 1982). Berry et al. (1981) slipped clear plastic sleeves over the Alsynite and applied the adhesive to the sleeves instead of directly to the trap.

The Williams trap, with its characteristic twopiece cross configuration, was modified by Broce (1988) into a cylinder trap made from a single piece of Alsynite. Gersabeck et al. (1982) developed a device for capturing stable flies for dispersal studies by modifying the cylinder trap with window screen and adding $\mathrm{CO}_{2}$ as an attractant. An octahedral configuration for capturing stable flies and face Glies, Musca autumnalis (De Geer), on different areas of the same trap was designed by Pickens \& Hayes (1984).

Tack Trap insect adhesive was used on the wooden panels tested by Bailey et al. (1973), and had

\footnotetext{
'This article reports the results of research only. Mention of a proprietary product or a pesticide does not constitute an endorsement or a recommendation for its use by the USDA, nor does it imply registration under FIFRA as amended.

I Insects Affecting Man and Animals Research Laboratory, USDA, P.O. Box 14565, Gainesville, Fla. 32604.

${ }^{3} J o h n$ A. Mulrennan, Sr. Research Laboratory, P.O. Box 15277 , Panama City, Fla. 32406-0277.
}

been widely accepted as the standard for use on the Williams sticky trap. Tack Trap has since been removed from the market, but another insect adhesive, Sticky Stuff, designed for use on fiberglass panels, is currently being sold.

Along the coastal areas of Northwest Florida and in other parts of the U.S., the public has expressed the need for a trap which could be used to eliminate the small numbers of nuisance stable flies that congregate around condominium swimming pools, backyard recreational facilities, and confined dogs. Because of the complex processes involved with adhesive application and cleanup, the standard Williams trap would not be suitable for this purpose. However, a commercial version of the Alsynite cylinder trap developed by Broce (1988) is being marketed.

Our studies were designed to compare the relative efficiency of the standard Williams trap with Tack Trap, the Williams trap with Sticky Stuff, and the cylinder trap being sold commercially. Samples of stable flies trapped on each device were analyzed to determine whether similar sex and physiological-age classes were being captured. Because the commercial trap and adhesives will undoubtedly be used for research purposes, these comparisons are necessary.

\section{Materials and Methods}

The four traps used in the studies were 1) Trap 1, Standard Williams trap (Alsynite panels coated with Tack Trap adhesive); 2) Trap 2, Williams trap coated with Olson Sticky Stuff adhesive; 3) Trap 3, Olson (cylinder) Sticky Fly Trap; and 4) Trap 4, Williams trap covered with Olson Sticky Sleeves.

The Williams traps used as the standard were made of two 28 by $43-\mathrm{cm}$ Alsynite panels ( 600 series, $1.14 \mathrm{~mm}$ [45 mil], flat, clear, Reichhold Plastics Division, Cleveland, Ohio), each with a 15- 
cm slit made parallel to the 28-cm side at the mid-point of the $43-\mathrm{cm}$ side. Tack Trap (Animal Repellents, Inc., Griffin, Ga.), a translucent polybutylene material, was thinned to a spreadable consistency with hexane and applied by paint roller to both sides of the panels at the laboratory. Coated panels were stacked in covered metal pans for transportation to the field. At the trapping sites, panels were joined at the slits to form the cross configuration (Trap 1) and mounted in vertical slits cut in 5 by $5-\mathrm{cm}$ wooden or $3.2-\mathrm{cm}$ PVC stakes. Stakes were placed so the bottom edge of Williams traps was approximately $90 \mathrm{~cm}$ above ground. This is $18 \mathrm{~cm}$ lower than Williams' (1973) original design, but was the standard height used in our other trapping studies.

Sticky Stuff (Olson Products, Medina, Ohio) is an acrylic formulation which is applied as a white liquid and which has a consistency similar to those of the commercially available white liquid glues. As Sticky Stuff dries, it becomes very sticky, and, unlike Tack Trap, turns clear. Sticky Stuff is ready to apply from its container and needs no thinning. Clean Alsynite panels normally used for the Williams traps were placed on stakes in the field as described above, and Sticky Stuff was then applied to trap surfaces with a $5-\mathrm{cm}$ paint brush (Trap 2).

The commercial cylinder trap, the Sticky Fly Trap (Olson Products Inc., Medina, Ohio), is similar to the one designed by Broce (1988), but consists of a single panel of clear corrugated instead of clear flat Alsynite. The Alsynite $0.89 \mathrm{~mm}$ [35 mil]) is formed into a cylinder about $30 \mathrm{~cm}$ high by $20 \mathrm{~cm}$ in diameter, and mounted in a slit on a single stake (Trap 3). The stake used in these studies was provided by the trap manufacturer and holds the bottom edge of the trap about $15-20 \mathrm{~cm}$ above the ground. Adhesives are not applied directly to this trap. Instead, a clear propylene Sticky Sleeve (Olson Products, Inc., Medina, Ohio), precoated with an adhesive substance similar to Sticky Stuff, is provided with the trap. The Sticky Sleeve is folded in half, sticky side in. To activate the trap, the Sticky Sleeve must be pulled open to expose the sticky side, wrapped around the trap sticky side out, and secured in place with metal paper clips.

Sticky Sleeves were also applied to the standard Williams trap. When the Alsynite panels are placed on a stake, each of the four wings measures approximately 20 by $28 \mathrm{~cm}$, or slightly smaller than a Sticky Sleeve. Sleeves were pulled open, wrapped sticky side out over the top of each wing, and secured at the bottom edge with a paper clip (Trap 4).

In a preliminary study, Traps 1 and 2 were used to compare Tack Trap and Sticky Stuff. Four consecutively numbered sites about $7 \mathrm{~m}$ apart were chosen along the perimeter of a fence adjacent to the holding pen at a dairy in Panama City (Bay County), Fla. The traps at the even-numbered sites were coated with Tack Trap and the traps at the odd-numbered sites were coated with Sticky Stuff.
Fresh traps were placed in the field, and the site sequence was reversed every week for four wk. Fly counts were made in the field while traps were still on the stakes. This study was performed in August 1984, and traps were in full sun except during the early morning and late afternoon hours.

The final study was done with all four traps. Four consecutively numbered sites were chosen along the perimeter of a fence adjacent to a holding pen and pole shed complex at a dairy near Chipley (Washington County), Fla. Sites 1 and 2 were about $7 \mathrm{~m}$ apart and located under a large tree which provided high shade all day. Sites 3 and 4 were also about $7 \mathrm{~m}$ apart under a large tree, but were in full sun until about 1300 hours, and high shade for the remainder of the day. Sites 1 and 2 were about $35 \mathrm{~m}$ from sites 3 and 4 . This study was done during June and July 1985 , on 12 consecutive week days.

Traps were randomly assigned to the four trapping sites, and fly counts were made in the field every $24 \mathrm{~h}$. After each count, the traps were moved to a different trapping site in accordance with a predesignated rotation schedule, and the used traps and adhesive-coated sleeves were replaced with fresh ones.

On four consecutive days, a maximum of 20 live flies were removed from each trap and returned to the laboratory on ice. Samples were collected between 1000 and 1100 hours when cattle were not in the vicinity. Females were subjected to physiological age grading (Scholl 1980) within $24 \mathrm{~h}$ after collection. Sex ratios were also recorded.

The only fly species monitored during the study was the stable fly. House fly, $M$. domestica (L.), populations on the dairies were small, and few were caught on the traps.

Data were analyzed with the General Linear Models (GLM) procedure; $\chi^{2}, t$, and Duncan's multiple range tests were used for separation of means ( $P=0.05$ unless otherwise specified) (SAS Institute 1982)

\section{Results and Discussion}

In the preliminary study, total fly catches and weekly mean fly catches per trap on the Williams traps with Tack Trap and Sticky Stuff were 5,954 and 745 and 6,676 and 835, respectively. Although the Williams trap with Sticky Stuff caught more flies than the Williams trap with Tack Trap, the difference was not significant.

When all four traps were compared, the Williams trap with Sticky Stuff again caught more flies than the Williams trap with Tack Trap; the difference was also not significant (Table 1). Numbers of flies caught on the cylinder trap and the Williams trap covered with the Sticky Sleeves were not significantly different, but both traps caught significantly fewer flies than either the Williams trap with Sticky Stuff or the Williams trap with Tack Trap. 
Broce (1988) found no significant difference between the numbers of stable flies captured by the Williams trap and the cylinder trap when both were covered with $0.25-\mathrm{mm}$ clear ionomer film (Flex-o-film; Flex-o-glass, Chicago, Ill.) coated with Sticky Stuff. This agrees well with our results; however, we found that the Williams trap covered with Sticky Sleeves captured the fewest flies of the three Williams-type traps we tested (Table 1). Application of Sticky Sleeves to Williams traps was more time-consuming than the application of an adhesive directly to the surface of the trap. In strong winds ( $>16 \mathrm{kph}$ ), this process became even more difficult. Use of the Sticky Sleeves might be warranted in situations where only one wing of the Williams trap is being used to capture flies.

When trapping efficiency (mean number of flies per $\mathrm{cm}^{2}$ ) was compared, the cylinder trap caught significantly more flies per $\mathrm{cm}^{2}$ than the traps having the Williams configuration (Table 1). This finding was also consistent with results reported by Broce (1988). The Williams traps used in our studies had 2.6 times the surface area of the cylinder trap, but the cylinder trap captured nearly 3 times as many flies per $\mathrm{cm}^{2}$ as the Williams trap covered with Sticky Sleeves. Trapping efficiency of the Williams trap with Sticky Stuff and the Williams trap with Tack Trap did not differ significantly; however, the trapping efficiency of the Williams trap covered with the Sticky Sleeves was significantly less than that of the other three traps.

Sex ratios (q:8) of flies captured on the Williams trap with Tack Trap, the Williams trap with Sticky Stuff, and the Williams trap covered with the Sticky Sleeves were 14:86 $(n=70), 8: 92(n=75)$, and $34: 66(n=70)$, respectively. All were significantly different $(P>0.01)$ from 50:50, with males always outnumbering the females. In contrast, the sex ratio (q:ठ) of flies captured on the cylinder trap was 50:50 $(n=70)(P>0.01)$. During a 10 -mo study performed at a dairy $<16 \mathrm{~km}$ from this dairy, Hogsette et al. (1989) found that the mean sex ratio $\left(8: 0^{8}\right)$ of stable flies captured on a standard Williams trap (comparable to Traps 1, 2, and 4 in conformation) was 22:78 when the trap was placed $10 \mathrm{~m}$ from a holding pen; females were more numerous than males only once in 33 trapping dates. Therefore, the consistent 50:50 sex ratio $(P>0.01)$ of all samples collected from the cylinder trap was decidedly different than what we had expected to find under these conditions, even during this relatively brief sampling period. Perhaps the difference in trap conformation (cross versus cylindrical) contributed to the disparity in sex ratios. Because traps were placed in the field concurrently and rotated through the same trapping sites, all traps were exposed to essentially the same large aggregation of stable flies. A difference in activity periods due to sex, i.e., more individuals of one sex active during our sampling period, could have been assumed if only Williams traps had been used, but results from the cylinder trap showed that both
Table 1. Total and mean number of stable flies captured, and stable flies captured per $\mathrm{cm}^{2}$ on the Olson cylinder and three Williams sticky traps

\begin{tabular}{lrrrr}
\hline \multirow{2}{*}{ Day } & \multicolumn{4}{c}{ Trap number $\Gamma^{a, b}$} \\
\cline { 2 - 5 } & 1 & 2 & 3 & 4 \\
\hline 1 & 276 & 220 & 211 & 89 \\
2 & 303 & 230 & 370 & 290 \\
3 & 410 & 325 & 394 & 283 \\
4 & 254 & 742 & 266 & 485 \\
5 & 270 & 690 & 241 & 498 \\
6 & 99 & 112 & 96 & 134 \\
7 & 404 & 410 & 34 & 190 \\
8 & 320 & 420 & 230 & 31 \\
9 & 384 & 431 & 97 & 108 \\
10 & 411 & 413 & 91 & 99 \\
11 & 364 & 390 & 115 & 105 \\
12 & 463 & 207 & 408 & 72 \\
$\Sigma$ & 3,958 & 4,590 & 2,553 & 2,384 \\
$\bar{x}$ & $330 \mathrm{~A}$ & $383 \mathrm{~A}$ & $213 \mathrm{~B}$ & $199 \mathrm{~B}$ \\
$\bar{x} / \mathrm{cm}^{2}$ & $0.07 \mathrm{~B}$ & $0.08 \mathrm{~B}$ & $0.74 \mathrm{~A}$ & $0.04 \mathrm{C}$ \\
\hline
\end{tabular}

${ }^{a}$ Means followed by the same letter are not significantly different $(P=0.05$; Duncan's multiple range test [SAS Institute 1982]).

$b_{1}$. Standard Williams trap (Alsynite panels coated with Tack Trap adhesive).

2. Williams trap coated with Olson Sticky Stuff adhesive.

3. Olson (cylinder) Sticky Fly Trap.

4. Williams trap covered with Olson Sticky Sleeves.

sexes were active. More study is needed, however, before additional inferences can be made.

The cylinder trap captured a greater percentage of nulliparous $(66 \%, n=35)$, unmated $(60 \%, n=$ 35) females than did Traps $1(36 \% ; 27 \%, n=11)$, $2(50 \% ; 33 \%, n=6)$, and $4(38 \% ; 33 \%, n=24)$. Hogsette et al. (1989) showed that the Williams trap usually (but not always) attracted nulliparous, unmated females, unless trap placement was very close to where stable flies were feeding on cattle. Although parity and fertility data do not permit a good comparison between the two trap conformations, it is important to note that the cylinder trap not only captured a large percentage of nulliparous, unmated females, but captured larger numbers of females from which to make these determinations than did Williams traps under similar conditions.

The Williams trap with Sticky Stuff performed as well as the standard Williams trap with Tack Trap. Therefore, researchers can accurately compare past or future trap samples collected with either adhesive. The cylinder trap can also be substituted for the standard Williams trap if a relative population estimate is the only desired result. The trapping efficiency of the cylinder trap was better than that of any of the Williams-type traps tested, but users will find the total number of tlies captured by the cylinder trap to be comparatively lower because of its smaller surface area. For the determination of other parameters, such as sex ratio, parity, and fertility status, placement studies must be performed with the cylinder trap to determine how it compares over time with the Williams trap and netted samples. 
The Sticky Sleeves were relatively easy to apply to the cylinder trap and precluded the necessity of removing the entire trap from the field for cleaning after each trapping interval. This eliminates the very unpopular and time-consuming job of removing adhesives and insects from traps as well as the disposal problems associated with the cleaning solvent.

\section{Acknowledgment}

We thank C. F. Bass and S. W. Campbell of the State of Florida, Department of Health and Rehabilitative Services, for their participation in these studies. Special thanks are due to $\mathbf{R}$. Baxley and A. Bylsma for giving us access to their dairies. Research was supported by $\mathrm{Co}$ operative Agreement No. 58-7B30-0-190 between USDA and the State of Florida, Department of Health and Rehabilitative Services.

\section{References Cited}

Bailey, D. L., T. L. Whitfield \& B. J. Smittle. 1973. Flight and dispersal of the stable fly. J. Econ. Entomol. 66: 410-411

Berry, I. L., P. J. Scholl \& J. I. Shugart. 1981. A mark and recapture procedure for estimating population sizes of stable fies. Environ. Entomol. 10: 8893.

Broce, A. B. 1988. An improved alsynite trap for stable flies, Stomoxys calcitrans (Diptera: Muscidae). J. Med. Entomol. 25: 406-409.

Gersabeck, E. F., R. W. Merritı \& J. D. Haefner. 1982. An efficient trap for collecting wild adult stable flies, Stomoxys calcitrans (Diptera: Muscidae), for markrelease studies. J. Med. Entomol. 19: 541-544.

Hogsette, J. A. 1983. An attractant self-marking device for marking field populations of stable flies with fluorescent dusts. J. Econ. Entomol. 76: 510-514.

Hogsette, J. A., J. P. Ruff \& C. J. Jones. 1989. Dispersal behavior of stable flies (Diptera: Muscidae), pp. 23-32. In J. J. Petersen \& G. L. Greene [eds.], Current status of stable fly (Diptera: Muscidae) research. Misc. Publ. Entomol. Soc. Am. No. 74.

Koehler, P. G. \& R. S. Patterson. 1982. Stable fly control with fiberglass panels. Fla. Coop. Ext. Serv. Livestock Prot. Pointer No. 14.

Meifert, D. W., R. S. Patterson, T. Whitfield, G. C. LaBrecque \& D. E. Weidhas. 1978. A unique attractant-toxicant system to control stable fly populations. J. Econ. Entomol. 71: 290-292.

Morgan, N. O., L. G. Pickens \& R. W. Thimijan. 1970. House flies and stable flies captured by two types of traps. J. Econ. Entomol. 63: 672-673.

Pickens, L. G. \& D. K. Hayes. 1984. Evaluation of a new face fly and stable fly (Diptera: Muscidae) trap which segregates the catch of the two species. Environ. Entomol. 13: 1256-1260.

Pickens, L. G., N. O. Morgan \& R. W. Miller. 1972. Comparison of traps and other methods for surveying density of populations of flies in dairy barns. J. Econ. Entomol. 65: 144-145.

Roberts, R. H. 1972. Relative attractiveness of $\mathrm{CO}_{2}$ and a steer to Tabanidae, Culicidae, and Stomoxys calcitrans (L.). Mosq. News. 32: 208-211.

SAS Institute. 1982. SAS user's guide: statistics. SAS Institute, Cary, N.C.

Scholl, P. J. 1980. A technique for physiologically age-grading female stable flies, Stomoxys calcitrans (L.). Univ. Nebr. IANR Res. Bull. 298.

Schreck, C. E., K. Posey \& H. K. Gouck. 1975. Evaluation of the electrocutor grid trap baited with carbon dioxide against the stable fly, Stomoxys calcitrans ( $L$.) (Diptera: Muscidae). J. Med. Entomol. 12: 339-340.

Williams, D. F. 1973. Sticky traps for sampling populations of Stomoxys calcitrans. J. Econ. Entomol. 66: 1279-1280.

Williams, D. F., O. Skov \& R. S. Patterson. 1977. Two traps for collecting live stable flies, Stomoxys calcitrans, in the field. Mosq. News. 37: 404-406.

Received for publication 14 January 1988; accepted 8 September 1989. 